Clinical trial

\title{
Predictive value of apoptosis, proliferation, HER-2, and topoisomerase II $\alpha$ for anthracycline chemotherapy in locally advanced breast cancer
}

\author{
G. Arpino ${ }^{1}$, D.R. Ciocca ${ }^{2}$, H. Weiss ${ }^{1}$, D.C. Allred ${ }^{1}$, P. Daguerre ${ }^{3}$, L. Vargas-Roig ${ }^{2}$, M. Leuzzi ${ }^{3}$, \\ F. Gago ${ }^{4}$, R. Elledge ${ }^{1}$, and S. K. Mohsin ${ }^{1}$ \\ ${ }^{1}$ Baylor College of Medicine, Houston, Texas, USA; ${ }^{2}$ Institute of Experimental Medicine and Biology of Cuyo, \\ Mendoza, Argentina; ${ }^{3}$ Hospital L. Lagomaggiore, Medical School, University of Cuyo, Mendoza, Argentina \\ ${ }^{4}$ Hospital Italiano, Medical School, University of Cuyo, Mendoza, Argentina
}

Key words: aptosis, breast cancer, neoadjuvant chemotherapy

Summary

Purpose. Laboratory evidence indicates that tumor growth depends on the balance between cell proliferation and cell death, and many anticancer agents may exert their therapeutic effect by decreasing proliferation and increasing apoptosis. Additionally, clinical observations indicate that overexpression of HER-2 or topoisomerase II $\alpha$ (topo II $\alpha$ ) may be predictors of better response to anthracyclines in breast cancer. The objective of this study was to determine if proliferation (Ki-67), apoptosis (TUNEL), and expression of HER-2 and topo II $\alpha$ are affected by anthracycline treatment, and if these molecular markers predict anthracycline responsiveness.

Experimental design. Thirty-three women with primary breast tumors $\geq 3 \mathrm{~cm}$ received either doxorubicin $(75 \mathrm{mg} /$ $\left.\mathrm{m}^{2}\right)$ or epirubicin $\left(120 \mathrm{mg} / \mathrm{m}^{2}\right)$ for 4 cycles before surgery. Clinical response was evaluated after 4 cycles of treatment. Changes in molecular markers were assessed from core needle biopsy taken before treatment (D0), at 24-48 h (D1) and on day 7 (D7) while on treatment, and from the surgical specimen excised on day 84 (D84) after the fourth cycle of chemotherapy.

Results. The overall clinical response rate was $51 \%$ (17 of 33 patients), with a $12 \%$ complete clinical response rate ( 4 of 33 patients). There were trends for tumors with higher apoptosis and topo II $\alpha$ at baseline (D0) to be more responsive to anthracyclines, $p=0.1$ and $p=0.08$, respectively. Median apoptosis increased from D0 to Dl $(p=0.06)$ while median Ki-67 decreased $(p=0.07)$. Overall, expression of HER-2 remained stable throughout the chemotherapy administration. By Day 84, topo II $\alpha$ had significantly decreased from baseline in responders, while it increased in non-responders, $p=0.03$.

Conclusions. In human primary breast cancer, anthracycline treatment causes an early increase in apoptosis and a decrease in proliferation. In this pilot study, higher apoptosis and topo IIaa levels in primary tumors were associated with greater responsiveness to anthracyclines, and topo II $\alpha$ levels declined in responsive tumors.

\section{Introduction}

Systemic chemotherapy and endocrine treatment for operable breast cancer significantly decreases the risk of relapse and death [1]. Systemic treatment before surgery (neoadjuvant therapy) has a number of theoretical advantages in breast cancer and can increase rates of breast conservation [2]. A decrease in the size of the primary tumor, indicating response to therapy, can be used as a surrogate marker of treatment efficacy on systemic micrometastases. Moreover, access to the primary tumor affords the opportunity for in vivo sensitivity testing and for obtaining tissue to study the mechanism of action of a therapy and molecular changes that might predict response. At present, it is not possible to identify at the outset those patients who are more likely to respond to a particular chemotherapy, or to determine which type of chemotherapy would be most effective in an individual patient. Established prognostic factors such as tumor size and nodal involvement are important indicators of the probability of micrometastatic spread and thus of breast cancer relapse and survival, but have not been predictive of sensitivity to treatment. Estrogen receptor and progesterone receptor expression are established predictive factors for endocrine therapy [3], but predictive markers for chemosensitivity are less well defined.

Anticancer agents may exert their therapeutic effect by decreasing proliferation, increasing apoptosis, or both. In breast cancers, chemotherapy has been found to induce apoptosis within $24 \mathrm{~h}$ of treatment [4]. Similarly, some studies have examined changes in tumor proliferation during treatment and found a decrease after some types of cytotoxic therapies [5-10]. While 
proliferation and apoptosis are relatively global assessments of cellular conditions and response, certain types of chemotherapy may target specific individual molecules that regulate these processes. Several clinical reports have suggested that breast cancer patients with tumors that overexpress HER-2 may derive more benefit from anthracycline-based therapy, suggesting that this molecule or pathway may be a target for this type of chemotherapy $[11,12]$. However, clinical studies have not been consistent, with one report linking HER-2 expression with resistance to chemotherapy [13]. Attempts to link HER-2 up-regulation to increased anthracycline sensitivity via manipulating expression in cell lines have also been inconsistent [14,15]. Topoisomerase II $\alpha$ (topo $I I \alpha$ ), a known molecular target for anthracyclines in experimental systems [16], is frequently co-amplified with HER-2 in breast cancer - the proximity of the topo II $\alpha$ and HER-2 genes on chromosome 17 provides a plausible, although unproven, mechanism for the putative link between HER-2 overexpression and anthracycline response [17].

The status of biological markers before treatment, together with changes as a result of treatment, may allow early prediction of sensitivity or resistance to neoadjuvant therapy and provide a window for understanding the mechanism of action of therapies. To explore these ideas, we have now measured apoptosis, proliferation (Ki-67), and HER-2 and topo II $\alpha$ expression in core needle biopsy specimens from primary breast cancers obtained before, during, and after single agent anthracycline chemotherapy. The study design allowed investigation of the specific effect of anthracycline chemotherapy in isolation. We hypothesized that anthracycline chemotherapy would result in a decrease in proliferation and an increase in apoptosis. Additionally, tumors with higher HER-2 or topo II $\alpha$ levels were expected to have increased sensitivity to anthracyclines.

\section{Methods}

\section{Patient population}

Patients with the following criteria were considered eligible for the present study: (1) histologically confirmed invasive breast cancer; (2) initial diagnosis and biopsy within 6 weeks of study entry; (3) clinical tumor size $\geq$ $3 \mathrm{~cm}$ at diagnosis; (4) adequate renal and hepatic function; and, (5) signed and approved informed consent. Exclusion criteria for the study were: (1) prior systemic therapy; (2) prior radiation therapy; (3) significant history of heart disease, serious illness, or infection; and, (4) inflammatory breast cancer.

From November 1996 to June 2000, 34 women were considered eligible and thus included for this molecular marker study that had been approved by the Institutional Review Boards (IRB) of the Lagomaggiore Hospital, Mendoza, Argentina. Of these, one was later excluded from the study because she had an inflammatory breast cancer without a defined tumor mass. Written informed consent was obtained from the remaining 33 eligible patients. Patients received doxorubicin $75 \mathrm{mg} / \mathrm{m}^{2}$ or epirubicin $120 \mathrm{mg} / \mathrm{m}^{2}$ for 4 cycles every 3 weeks before surgery. Patients received 6 cycles of CMF postoperatively, and adjuvant hormonal therapy after surgery according to the investigators' judgment based on estrogen and progesterone receptor analysis. Women who had breast-conserving surgery were given postoperative radiotherapy to the breast.

\section{Staging and response}

Clinical staging and size of the primary tumor were recorded by two clinicians following WHO guidelines at the start of treatment, at each cycle, and after completion of four cycles of neoadjuvant chemotherapy. Response was defined according to the following criteria: complete response (CR) was defined as no residual palpable disease, partial response (PR) as greater than $50 \%$ reduction in bi-dimensional measurements, stable disease (SD) as less than $50 \%$ reduction or $25 \%$ increase in tumor size, and progressive disease (PD) as greater than $25 \%$ in crease in tumor size. Tumor overall response (OR) was defined as $\mathrm{CR}$ or PR, and nonresponse as $\mathrm{SD}$ or $\mathrm{PD}$.

\section{Timing and collection of samples}

For most patients, core needle biopsies of the primary breast tumors were performed using a 14-gauge springloaded needle (C.R. Bard, Inc., Covington, GA). One to three cores, $1 \mathrm{~mm}$ in diameter and 3-10 $\mathrm{mm}$ in length, were generally obtained. On some initial patients, a smaller gauge needle was used; when inadequate amounts of cells were noted in some specimens, investigators were advised to use 14-gauge needles for subsequent patients. Needle biopsy material and tissue from surgery were immediately fixed in $10 \%$ buffered formalin.

Molecular markers were assessed from biopsies obtained before treatment (Day 0), at 24-48 h (Day 1), on day 7 (Day 7), and at surgical excision (Day 84, after 4 cycles of chemotherapy). Timing at either 24 or $48 \mathrm{~h}$ was based on availability of the patients for repeat biopsies. For day 0 samples, 2 patients had only DCIS and 6 had missing blocks, and these were excluded from further analyses. In addition, 8 had relatively small number of tumor cells and therefore only certain biomarkers could be evaluated and compared with samples at other time points. For day 1 samples, one had DCIS only, 11 had no tumor, 5 had very few tumor cells, and 16 were of good quality. For day 7 samples, 3 had missing blocks, one had DCIS only, 8 had no tumor cells, 7 had very few tumor cells, and 14 were of good quality. At day 84, 26 cases had residual invasive tumor cells for biomarker evaluation, including 4 cases with relatively few tumor cells on $\mathrm{H}$ and $\mathrm{E}$ examination, and 
these were not used for biolmarker evaluation; therefore, 22 cases were unavailable for staining on Day 22. Immunohistochernical (IHC) scoring (by SKM and DCA) was performed in a blinded fashion without any knowledge of the patients' clinical data, Since some specimens were too small, or of inadequate cellularity to be analyzed by IHC, data is not available at all time points for some patients.

Topo II $\alpha$ analysis was not included in the initial study design but was added later, after the molecular and clinical findings of a possible role of this protein in the anthracycline sensitivity became apparent. Because of limitations of tissue availability and because tissue from some cores had been exhausted from previous study, only specimens from pretreatment and Day 84 could be evaluated for this marker on tissue that remained.

\section{Immunohistochemical analysis for the biomarkers}

Immunohistochemistry (IHC) was performed on $4-\mu \mathrm{m}$ thick sections after deparaffinization. The information on primary antibodies is summarized in Table 1. All IHC analyses except HER-2 required antigen retrieval in a pressure-cooker for 5 min using Tris- $\mathrm{HCl}$ buffer at $\mathrm{pH}$ 9.0. Endogenous peroxidase was blocked with $3 \%$ hydrogen peroxide and non-specific staining with avidin-biotin block (Vector Labs, CA). Sections were then incubated with primary antibody for $60 \mathrm{~min}$ at room temperature, followed by secondary antibody at 1:200 dilution for $30 \mathrm{~min}$. Labeled streptavidin-horseradish peroxidase (DakoCytomation, CA) at 1:200 dilution was applied next, and the IHC reaction was developed with $\mathrm{DAB}+$ (DakoCytomation, CA) for $15 \mathrm{~min}$ and enhanced with $0.2 \%$ osmium tetroxide for $30 \mathrm{~s}$. Sections were counterstained with light methyl green and coverslipped.

For TUNEL assay, after antigen retrieval, sections were treated with TdT buffer for $5 \mathrm{~min}$ and then incubated with TdT-d-UTP biotin 16 (Roche Diagnostics, Switzerland) for $2 \mathrm{~h}$ and $15 \mathrm{~min}$ at $37^{\circ} \mathrm{C}$. The remainder of the procedure was identical to other markers.

\section{Interpretation of IHC staining}

For HER-2, IHC stained slides were scored using 'Allred score' with a range of $0-8$ and a cut-off of $\geq 3$, corresponding to $10 \%$ cells with complete membrane staining, as previously validated [18]. For Ki67 (MIB-1), topo II $\alpha$, and TUNEL, 200-500 cells were point-counted under the microscope and results were recorded as percent positive. For MIB-1 a cut-off of $20 \%$ was used as described before to define low versus high proliferation rate $[19,20]$. Since no validated cut-offs exist for topo II $\alpha$ or TUNEL, the median scores in this patient cohort were used as the cut-off to define low versus high values (Table 1).

\section{Statistical methods}

Baseline apoptosis, Ki-67, HER-2, and topo II $\alpha$ were analyzed as possible predictors of response by the Wilcoxon rank-sum test. Sequential measurements of change in apoptosis (\%) and in expression of $\mathrm{Ki}-67(\%)$ and HER-2 (IHC score) at Day 1, Day 7, and Day 84 were calculated by comparing with the pretreatment levels (change equals posttreatment minus pretreatment scores) using the Wilcoxon signed-rank test. Changes in topo II $\alpha$ expression were calculated by comparing DO versus D84. The changes in marker levels between responders and non-responders were then considered as predictors of response based on the Wilcoxon rank-sum test.

\section{Results}

Table 2 describes the clinical and tumor characteristics. The median age of patients enrolled in this study was 50 years (range 32-69 years), and $51 \%$ of women were postmenopausal. The median tumor size was $6 \mathrm{~cm}$ (range 3-9 cm) and, not unexpectedly, 70\% (21) of the study population had clinical lymph node involvement at the time of diagnosis.

After 4 cycles of anthracycline chemotherapy at about 3 months the clinical overall objective response rate was $51 \%$ (17 of 33) which is in an expected range, with median tumor size of $6 \mathrm{~cm}$. The majority of patients $(64 \%)$ had a lumpectomy plus axillary node dissection as their surgical procedure, and $88 \%$ of residual tumors were invasive ductal carcinomas.

Based on cut-offs for molecular assessments defined in Table 1, at baseline $65 \%(13 / 20)$ of tumors had high proliferation rate $(\mathrm{Ki}-67>20 \%), 25 \%(6 / 24)$ overexpressed HER-2, $63 \%(10 / 16)$ had high levels of topo II $\alpha$, and $55 \%(12 / 22)$ had a high apoptosis rate. Possibly because of small numbers in the analysis, none of the tumor markers at baseline were found to be statistically significant predictors of chemotherapy response

Table 1. Details of the immunohistochemical assays for the molecular markers

\begin{tabular}{|c|c|c|c|c|c|}
\hline Marker & Antibody clone & Dilution of primary antibody & Source & Scoring & Cut-off \\
\hline $\mathrm{Ki}-67$ & MIB-1 & $1: 200$ & DakoCytomation & $\%$ & $20 \%$ \\
\hline HER-2 & Tab 250 & $1: 200$ & Zymed & Allred score & $\geq 3(>10 \%)$ \\
\hline Topo II $\alpha$ & $3 \mathrm{~F} 6$ & $1: 100$ & Novocastra & $\%$ & $5 \%$ \\
\hline TUNEL & - & $1: 400$ & Roche Diagnostics & $\%$ & $0.4 \%$ \\
\hline
\end{tabular}


Table 2. Clinical and tumor characteristics of locally advanced breast cancer patients who received single agent anthracycline-based neoadjuvant chemotherapy

\begin{tabular}{|c|c|c|}
\hline & $\%$ & $n$ \\
\hline \multicolumn{3}{|l|}{ Age } \\
\hline Median & $50 \mathrm{yrs}$ & \\
\hline Range & $32-69$ yrs & \\
\hline \multicolumn{3}{|l|}{ Menopausal status } \\
\hline Premenopausal & $49 \%$ & $(16)$ \\
\hline Postmenopausal & $51 \%$ & $(17)$ \\
\hline \multicolumn{3}{|l|}{ Tumor size } \\
\hline Median & $6 \mathrm{~cm}$ & \\
\hline Range & $3-9 \mathrm{~cm}$ & \\
\hline \multicolumn{3}{|l|}{ Clinical Nodal statust } \\
\hline Node-negative & $30 \%$ & $(12)$ \\
\hline Node-positive & $70 \%$ & $(21)$ \\
\hline \multicolumn{3}{|l|}{ Clinical response } \\
\hline \multicolumn{3}{|l|}{ (WHO classification) } \\
\hline Complete response (CR) & $12 \%$ & (4) \\
\hline Partial response (PR) & $39 \%$ & (13) \\
\hline Stable disease (SD) & $49 \%$ & $(16)$ \\
\hline Progressive disease (PD) & $0 \%$ & $(0)$ \\
\hline Overall response rate & $51 \%$ & $(17)$ \\
\hline \multicolumn{3}{|l|}{$(C R+P R)$} \\
\hline \multicolumn{3}{|l|}{ Type of Surgery } \\
\hline Lumpectomy & $64 \%$ & $(21)$ \\
\hline Modified radical mastectomy & $36 \%$ & (12) \\
\hline \multicolumn{3}{|l|}{ Histology in initial } \\
\hline \multicolumn{3}{|l|}{ core biopsy } \\
\hline Infiltrating ductal carcinoma & $91 \%$ & $(30)$ \\
\hline Infiltrating lobular carcinoma & $9 \%$ & (3) \\
\hline
\end{tabular}

(Table 3); however, there was a trend for tumors with higher levels of topo II $\alpha$ to respond to anthracycline chemotherapy, median topo $\mathrm{II} \alpha=17 \%$ versus $3.5 \%$ in responders versus non-responders, respectively, $p=$ 0.08. There was also a trend for tumors with higher apoptosis to be more responsive - median apoptosis was $0.9 \%$ in responders versus $0.2 \%$ in non-responders, $p=$ 0.1 . Two of 13 responders were HER-2 positive, versus 2 of 11 of the non-responders.

Serial biopsies allowed for monitoring changes over time in median Ki-67, apoptosis, HER-2, and topo II $\alpha$. Median changes in molecular markers compared to
Table 4. Median changes over time in levels of Ki67, apoptosis, HER-2, and Topo II $\alpha$ induced by anthracyclines therapy

\begin{tabular}{llll}
\hline & $\begin{array}{l}\delta \text { Day } 1 \\
\text { median }\end{array}$ & $\begin{array}{l}\delta \text { Day } 7 \\
\text { median }\end{array}$ & $\begin{array}{l}\delta \text { Day } 84 \\
\text { median }\end{array}$ \\
\hline Ki-67 $(\%)$ & $-1(n=14)^{*}$ & $-7(n=13)$ & $-6.5(n=18)$ \\
$\begin{array}{l}\text { Apoptosis }(\%) \\
\text { HER-2 }\end{array}$ & $0(n=12)$ & $0(n=17)$ & $0(n=22)$ \\
$\begin{array}{l}\text { IHC score }) \\
\text { Topo II } \alpha(\%)\end{array}$ & ND & ND & $-1.5(n=16)$ \\
\hline
\end{tabular}

$\delta$ Day 1: Difference between Day 1 value and Day 0 value; $\delta$ Day 7 : Difference between Day 7 value and Day 0 value; $\triangle$ Day 84 : Difference between Day 84 value and Day 0 value.

ND: not done.

${ }^{*} p=0.07 ; *{ }^{*} p=0.06$.

baseline are summarized in Table 4. As expected, decreases in proliferation were noted early, within 24-48 $\mathrm{h}$ after administration of anthracycline chemotherapy. By day 1 proliferation tended to decrease (median $\triangle=-1.0 \%, p=0.07$ ) and apoptosis to increase (median $\triangle=+0.65 \%, p=0.06$ ) in response to chemotherapy. These observations were maintained over time although none achieved statistical significance. HER-2 remained unchanged.

Topo II $\alpha$ levels were only available on Day 0 and 84 . Overall, topo II $\alpha$ showed only a small insignificant decrease during this time. However, in patients responding to chemotherapy, the staining for topo II $\alpha$ decreased from pretreatment to Day 84 (median $\triangle=-9.5 \%$ ), while in patients not responding to chemotherapy, topo II $\alpha$ staining increased (median $\triangle=+4.5 \%, p=0.03$ ) (Table 5). None of the changes in the other markers in the study (apoptosis, proliferation, and HER-2 status) were significantly different between responders and nonresponders (Table 5).

\section{Discussion}

The results of the present study indicate that in human breast cancer, treatment with anthracycline chemotherapy causes a very early increase in apoptosis and decrease in proliferation. Higher apoptosis in the primary tumor is associated with tumor responsiveness and may indicate a lower threshold for chemotherapy-triggered

Table 3. Predictive value of biomarkers at baseline

\begin{tabular}{|c|c|c|c|c|c|}
\hline \multirow[t]{2}{*}{ Marker } & \multicolumn{2}{|c|}{ Responders } & \multicolumn{2}{|c|}{ Non-responders } & \multirow[t]{2}{*}{$p$-value } \\
\hline & $N$ & Median ( $\%$ or IHC score) & $N$ & Median (\% or IHC score) & \\
\hline Ki-67 (\%) & 11 & 21.0 & 9 & 23.0 & 0.8 \\
\hline Apoptosis $(\%)$ & 11 & 0.9 & 11 & 0.2 & 0.1 \\
\hline HER-2 (IHC score) & 13 & 0 & 11 & 0 & 0.7 \\
\hline Topo II $\alpha(\%)$ & 8 & 17 & 8 & 3.5 & 0.08 \\
\hline
\end{tabular}


Table 5. Median changes over time in levels of Ki-67, HER-2, apoptosis, and Topo II $\alpha$ according to clinical response

\begin{tabular}{|c|c|c|c|c|c|}
\hline \multirow[t]{2}{*}{ Marker } & & \multicolumn{2}{|c|}{ Responders } & \multicolumn{2}{|c|}{$\begin{array}{l}\text { Non- } \\
\text { Responders }\end{array}$} \\
\hline & & $N$ & Median & $N$ & Median \\
\hline \multirow[t]{3}{*}{ Ki-67 (\%) } & $\Delta$ Day 1 & 7 & -5 & 7 & -1 \\
\hline & $\Delta$ Day 7 & 5 & 6.8 & 8 & -12.0 \\
\hline & $\Delta$ Day 84 & 10 & -6.5 & 8 & -2.5 \\
\hline \multirow[t]{3}{*}{ HER-2 } & $\Delta$ Day 1 & 5 & 0 & 7 & 0 \\
\hline & $\Delta$ Day 7 & 7 & 0 & 10 & 0 \\
\hline & $\Delta$ Day 84 & 12 & 0 & 10 & 0 \\
\hline \multirow[t]{3}{*}{ Apoptosis $(\%)$} & $\Delta$ Day 1 & 6 & 0.85 & 7 & 0.6 \\
\hline & $\Delta$ Day 7 & 5 & 0.7 & 8 & 0.35 \\
\hline & $\Delta$ Day 84 & 10 & 0.25 & 10 & 0.3 \\
\hline Topo II $\alpha(\%)^{*}$ & $\Delta$ Day 84 & 8 & -9.5 & 8 & 4.45 \\
\hline
\end{tabular}

$* p=0.03$.

cell death. In addition, tumors and cells with high topo II $\alpha$ levels may be selectively sensitive to anthracyclines.

This study had a number of unique aspects, providing complementary data to laboratory results. The trial was designed to study the specific effects and mechanisms of a single chemotherapeutic agent. Most prior clinical studies used combination chemotherapy, making it impossible to focus on the effect of a particular agent. Also, testing was done on intact human breast tissue, with vasculature, stroma, and other components, conditions that cannot be replicated in laboratory experiments.

The balance between programmed cell death (apoptosis) and cell proliferation determines tumor growth, and any, alteration between the two factors is a key element for the uncontrolled expansion of malignant tumors $[21,22]$. Laboratory studies with cell lines indicate that many anticancer agents act by inducing apoptosis, and failure of induction of apoptosis in vitro by chemotherapeutic agents is a mechanism of chemoresistance and has been used for testing the efficacy of specific or novel therapies $[23,24]$. The central biochemical event of apoptosis is endonucleolysis, which results in DNA cleavage into oligonucleosome-sized fragments [25]. These fragments form the basis of TUNEL assay, which has been a reproducible method to assess programmed cell death in clinical samples [26]. In the current study, apoptosis mainly increased in the first 24-48 h after treatment, corroborating laboratory findings of early induction of apoptosis within few hours [27]. A previous neoadjuvant study has reported that an increase in apoptosis in the first $24 \mathrm{~h}$ of treatment is a significant predictor of tumor response to two different well known chemotherapeutic agents: mitoxantrone and methotrexate [28]. Another study showed the same findings following treatment with tamoxifen [29], thus suggesting that the predictive value of apoptosis is probably not restricted to specific drugs but rather is valid for many drugs with different mechanisms of action.

Changes in proliferation have also been correlated with treatment in several studies [5-10]. For instance, a decrease in $\mathrm{Ki}-67$, a specific nuclear antigen expressed only on proliferating cells (late G1-, S-, and G2-phases of the cell cycle) [30], has been found to be a significant predictor of objective response to chemotherapy [31], In the present report, overall proliferation, as measured by $\mathrm{Ki}-67$, tended to decrease by the first $24-48 \mathrm{~h}$ after treatment.

With regard to HER-2, contrasting results have been reported on its predictive role in anthracycline-treated patients. Some large studies have reported a positive association between HER-2 overexpression and favorable response to anthracyclines in breast cancer $[11,12,32]$. However, the existence of that association and its underlying mechanism remain controversial [33]. In the present report, HER-2 overexpression did not predict a favorable (or unfavorable) response to anthracyclines. Furthermore, HER-2 status did not change during the course of therapy, suggesting that the HER-2 protein is not a target for anthracyclines.

Finally, this data supports the idea that rather than HER-2, topo II $\alpha$ is actually an important therapeutic target of anthracyclines, and that levels of topo II $\alpha$ are important determinants of sensitivity of breast cancer to anthracycline-based therapy. Since topo II $\alpha$ is a known target of anthracyclines in experimental models, tumors with higher levels or a higher proportion of cells with increased expression should be more sensitive and respond better to the drug. Cells within the tumor that preferentially express topo II $\alpha$ may be selectively killed by drug exposure, thus accounting for the observation of falling levels associated with sensitivity. Some other studies also indicate that topo II $\alpha$ overexpression, as well as gene amplification, are important determinants of sensitivity of breast cancer to anthracyclines, [34] though findings have not always been consistent $[35,36]$. Part of this disparity may be methodological, and the optimal assay for topo. II $\alpha$ has not been validated.

This was a pilot study, which began in 1996. The study has a number of limitations; one of which is the relatively small number of patients that could be recruited at a single site, despite a 4-year effort. Expanding such studies to multiple centers could be useful, especially as the use of neoadjuvant therapy in operable breast cancer becomes more widely accepted in the clinic. In earlier stages of the study, some specimens were too small or of inadequate cellularity for analysis, further reducing the power to detect biologically, meaningful differences. Careful attention to technique, experience, and the use of a fully automated, 14-gauge spring-loaded biopsy needle can improve cellular adequacy. Also, in other, later studies, we have found that cellular adequacy can be substantially improved if 6 cores are obtained rather than only 1 or 2 , as was done for most patients in the present study. IHC-based assessment of markers limited the number of markers that could be examined, and all specimens were preserved in formalin and paraffin. In the future, flash freezing of tissue and applying high through-put molecular techniques will allow analysis of thousands of 
genes and proteins simultaneously, rather than just a few by IHC.

In conclusion, this small prospective clinical study supports the idea that neoadjuvant chemotherapy provides a platform from which to discover predictive markers of chemotherapy response. Because the tumor is accessible for initial and serial biopsies, assessment of molecular markers before and after treatment is feasible and should become widely applied to explore the mechanism of action of novel agents and to identify molecular profiles of changes that would predict response. From molecular mechanisms, pathways of sensitivity or resistance can be understood, and therapies can be rationally optimized and more rapidly improved. Furthermore, molecular markers could be used to select the optimal chemotherapeutic agent, thus sparing patients the side effects and morbidity of ineffective, or less effective, treatment.

\section{Acknowledgements}

This study was supported by grants from the National Research Council (CONICET PIP 2897), and the Argentine Foundation for Cancer Research, a SPORE Career Development Award (P50 CA58183), and a Komen Foundation Postdoctoral Fellowship (PDF0403061).

\section{References}

1. Systemic treatment of early breast cancer by hormonal, cytotoxic, or immune therapy. 133 randomized trials involving 31,000 recurrences and 24,000 deaths among 75,000 women. Early Breast Cancer Trialists' Collaborative Group. Lancet 339(8785): 71-85, 1992

2. Wolmark N, Wang J, Mamounas E, Bryant J, Fisher B: Preoperative chemotherapy in patients with operable breast cancer: nineyear results from National Surgical Adjuvant Breast and Bowel Project B-18. J Natl Cancer Inst Monogr (30): 96-102, 2001

3. Mouridsen H, Palshof T, Patterson J., Battersby L: Tamoxifen in advanced breast cancer. Cancer Treat Rev 5(3): 131-141, 1978

4. Ellis PA, Smith IE, McCarthy K, Detre S, Salter J, Dowsett M: Preoperative chemotherapy induces apoptosis in early breast cancer. Lancet 349(9055): 849, 1997

5. O'Reilly SM, Camplejohn RS, Rubens RD, Richards MA: DNA flow cytometry and response to preoperative chemotherapy for primary breast cancer. Eur J Cancer 28(2-3): 681-683, 1992

6. Remvikos Y, Vielh P, Padoy E, Benyahia B, Voillemot N, Magdelenat $\mathrm{H}$ : Breast cancer proliferation measured on cytological samples: a study by flow cytometry of S-phase fractions and BrdU incorporation. Br J Cancer 64(3): 501-507, 1991

7. Spyratos F, Briffod M, Tubiana-Hulin M, Andrieu C, Mayras C, Pallud C, Lasry S, Rouesse J: Sequential cytopunctures during preoperative chemotherapy for primary breast carcinoma. II. DNA flow cytometry changes during chemotherapy, tumor regression, and short-term follow-up. Cancer 69(2): 470-475, 1992

8. Chevillard S, Lebeau J, Pouillart P, Toma Cde, Beldjord C, Asselain B, Klijanienko J, Fourquet A, Magdelenat H, Viehl P: Biological and clinical significance of concurrent p53 gene alterations, MDR1 gene expression, and S-phase fraction analyses in breast cancer patients treated with primary chemotherapy or radiotherapy. Clin Cancer Res 3(12 Pt 1): 2471-2478, 1997
9. Chevillard S, Pouillart P, Beldjord C, Asselain B, Beuzeboc P, Magdelenat H, Vieh1 P: Sequential assessment of multidrug resistance phenotype and measurement of S-phase fraction as predictive markers of breast cancer response to neoadjuvant chemotherapy. Cancer 77(2): 292-300, 1996

10. Rasbridge SA, Gillett CE, Seymour AM, Patel K, Richards MA, Rubens RD, Millis RR: The effects of chemotherapy on morphology, cellular proliferation, apoptosis and oncoprotein expression in primary breast carcinoma. Br J Cancer 70(2): 335-341, 1994

11. Thor AD, Berry DA, Budman DR, Muss HB, Kute T, Henderson IC, Barcos M, Cirrincione C, Edgerton S, Allred C, Norton L, Liu E: erbB-2, p53, and efficacy of adjuvant therapy in lymph nodepositive breast cancer. J Natl Cancer Inst 90(18): 1346-1360, 1998

12. Paik S, Bryant J, Park C, Fisher B, Tan-Chiu E, Hyams D, Fisher M, Lippman D, Wickerham D, Wolmar N: erbB-2 and response to doxorubicin in patients with axillary lymph node-positive, hormone receptor-negative breast cancer. J Natl Cancer Inst 90(18): 1361-1370, 1998

13. Vargas-Roig LM, Gago FE, Tello O, Martin de Civetta MT, Ciocca DR: c-erbB-2 (HER-2/neu) protein and drug resistance in breast cancer patients treated with induction chemotherapy. Int $\mathbf{J}$ Cancer 84(2): 129-134, 1999

14. Witters LM, Santala SM, Engle L, Chinchilli V, Lipton A: Decreased response to paclitaxel versus docetaxel in HER-2/neu transfected human breast cancer cells. Am J Clin Oncol 26(1): 5054, 2003

15. Pegram MD, Finn RS, Arzoo K, Beryt M, Pietras RJ, Slamon DJ: The effect of HER-2/neu overexpression on chemotherapeutic drug sensitivity in human breast and ovarian cancer cells. Oncogene 15(5): 537-547, 1997

16. Harris LN, Yang L, Liotcheva V, Pauli S, Iglehart JD, Colvin OM, Hsieh TS: Induction of topoisomerase II activity after ErbB2 activation is associated with a differential response to breast cancer chemotherapy. Clin Cancer Res 7(6): 1497-1504, 2001

17. Jarvinen TA, Tanner M, Rantanen V, Barlund M, Borg A, Grenman S, Isola J: Amplification and deletion of topoisomerase IIalpha associate with ErbB-2 amplification and affect sensitivity to topoisomerase II inhibitor doxorubicin in breast cancer. Am J Pathol 156(3): 839-847, 2000

18. Allred DC, Clark GM, Tandon AK, Molina R, Tormey DC, Osborne CK, Gilchrist KW, Mansour EG, Abeloff M, Eudey L, McGuire WL: HER-2/neu in node-negative breast cancer: prognostic significance of overexpression influenced by the presence of in situ carcinoma. J Clin Oncol 10: 599-605, 1992

19. Seshadri R, Leong AS, McCaul K, Firgaira FA, Setlur V, Horsfall DJ: Relationship between p53 gene abnormalities and other tumour characteristics in breast-cancer prognosis. Int J Cancer 69(2): 135-141, 1996

20. Veronese SM, Maisano C, Scibilia J: Comparative prognostic value of Ki-67 and MIB-1 proliferation indices in breast cancer. Anticancer Res 15(6B): 2717-2722, 1995

21. Fisher DE: Apoptosis in cancer therapy: crossing the threshold. Cell 78(4): 539-542, 1994

22. Kerr JF, Wyllie AH, Currie AR: Apoptosis: a basic biological phenomenon with wide-ranging implications in tissue kinetics. Br J Cancer 26(4): 239-257, 1972

23. Ohmori T, Podack ER, Nishio K, Takahashi M, Miyahara Y, Takeda Y, Kubota N, Funayama Y, Ogasawara H, Chira T: Apoptosis of lung cancer cells caused by some anti-cancer agents (MMC, CPT-11, ADM) is inhibited by bcl-2. Biochem Biophys Res Commun 192(1): 30-36, 1993

24. Walton MI, Whysong D, O'Connor PM, Hockenbery D, Korsmeyer SJ, Kohn KW: Constitutive expression of human Bcl-2 modulates nitrogen mustard and camptothecin induced apoptosis. Cancer Res 53(8): 1853-1861, 1993

25. Compton MM: A biochemical hallmark of apoptosis: internucleosomal degradation of the genome. Cancer Metastasis Rev 11(2): 105-119, 1992

26. Dowsett M, Detre S, Ormerod MG, Ellis PA, Mainwaring PN, Titley JC, Smith IE: Analysis and sorting of apoptotic cells from 
fine-needle aspirates of excised human primary breast carcinomas. Cytometry 32(4): 291-300, 1998

27. Symmans FW: Breast cancer response to paclitaxel in vivo. Drug Resist Updat 4(5): 297-302, 2001

28. Chang J, Ormerod M, Powles TJ, Alfred DC, Ashley SE, Dowsett M: Apoptosis and proliferation as predictors of chemotherapy response in patients with breast carcinoma. Cancer 89(11): 21452152, 2000

29. Chang J, Powles TJ, Alfred DC, Ashley SE, Makris A, Gregory RK, Osborne CK, Dowsett M: Prediction of clinical outcome from primary tamoxifen by expression of biologic markers in breast cancer patients. Clin Cancer Res 6(2): 616-621, 2000

30. Gerdes J, Lelle RJ, Pickartz H, Heidenreich W, Schwarting R, Kurtsiefer L, Stauch G, Stein H: Growth fractions in breast cancers determined in situ with monoclonal antibody Ki-67. J Clin Pathol 39(9): 977-980, 1986

31. Chang J, Powles TJ, Alfred DC, Ashley SE, Clark GM, Makris A, Assersohn L, Gregory RK, Osborne CK, Dowsett M: Biologic markers as predictors of clinical outcome from systemic therapy for primary operable breast cancer. J Clin Oncol 17(10): 30583063, 1999

32. Muss HB, Thor AD, Berry DA, Kute T, Liu ET, Koerner F, Cirrincione CT, Budman DR, Wood WC, Barcos M: c-erbB-2 expression and response to adjuvant therapy in women with nodepositive early breast cancer. N Engl J Med 330(18): 1260-1266, 1994
33. Vincent-Salomon A, Carton M, Freneaux P, Palangie T, Beuzeboc P, Mouret E, Cremoux Pde, Coue O., Zafrani B, Nicolas A, Clough K, Fourquet A, Pouillart P, Sastre-Garau X: ERBB2 overexpression in breast carcinomas: no positive correlation with complete pathological response to preoperative high-dose anthracycline-based chemotherapy. Eur J Cancer 36(5): 586-591, 2000

34. Coon JS, Marcus E, Gupta-Burt S, Seelig S, Jacobson K, Chen S, Renta V, Fronda G, Preisler HD: Amplification and overexpression of topoisomerase II alpha predict response to anthracyclinebased therapy in locally advanced breast cancer. Clin Cancer Res 8(4): 1061-1067, 2002

35. Dingeinans AM, Witlox MA, Stallaert RA, Valk Pvan der, Postmus PE, Giaccone G: Expression of DNA topoisotnerase IIalpha and topoisomerase IIbeta genes predicts survival and response to chemotherapy in patients with small cell lung cancer. Clin Cancer Res 5(8): 2048-2058, 1999

36. Klumper E, Giaccone G, Pieters R, Broekema G, Ark-Otte Jvan, Wering ERvan, Kaspers GJ, Veerman AJ: Topoisomerase II alpha gene expression in childhood acute lymphoblastic leukemia. Leukemia 9(10): 1653-1660, 1995

Address for offprints and correspondence: Dr R.M. Elledge, Breast Care Center, 6550 Fannin Street, 7th Floor, Suite 701, Houston, TX 77030, USA; Tel:: (713)798-1655; Fax: (713)798-884; E-mail: relledge@, breastcenter.tmc.edu 
Reproduced with permission of the copyright owner. Further reproduction prohibited without permission. 